\title{
A Case of Autoimmune Hypoglycemia in Switzerland
}

Adrian Stefanescu* and Pierre-Alexandre Bart

Department of Internal Medicine, University Hospital Lausanne, Switzerland

\begin{abstract}
In this report, we describe a white man with symptomatic hypoglycemia whose medical work-up revealed an excessively elevated serum insulin level $(867 \mathrm{mIU} / \mathrm{l})$. The need to measure IAA in patients with extraordinarily high measured levels of total insulin is essential because of the possible artifactual elevation (in a conventional insulin immunoassay) caused by IAA. In the present case, the elevated IAA level (>50 kIU/I) confirmed the diagnosis of autoimmune hypoglycemia and allowed to avoid unnecessary surgical intervention.
\end{abstract}

Keywords: Insulin autoimmune syndrome; Hirata disease; Insulin autoimmune antibody

\section{Introduction}

The insulin autoimmune syndrome (IAS), also known as Hirata disease, is a rare cause of hypoglycemia, particularly in non-Asian populations, characterized by spontaneous hypoglycemia, extremely high insulin levels and the presence of circulating native insulin autoimmune antibody (IAA) in patients who have never been exposed to exogenous insulin [1]. These antibodies first bind insulin, forming a complex, and subsequently, regardless of the glucose levels, release it causing hypoglycemia. IAS is considered to be the third greatest cause of hypoglycemia in Japan following insulinoma and extrapancreatic neoplasms and is increasingly being recognized worldwide in nonAsian populations [2]. The cases reported in Japan have shown strong association between IAS and HLA-DR4 status, haplotype 20 times more common in Asians compared with non-Asian subjects, or the use of medications containing sulfhydryl (thiol) group. Cases reported from other parts of the world are more frequently associated with autoimmune disorders and plasma cell dyscrasias $[3,4]$. The majority of the cases reported outside Asia come from Europe (50\%) and the United States (41\%). Overall, IAS affects men and women equally and is seen more frequently in patients older than 40 years of age [5].

\section{Case Report}

An 88-year-old retired Caucasian man with Hispanic origins, presented an episode of symptomatic hypoglycemia at home. He was found by a family member outside his bed, on the floor, in a confused and agitated state. When the emergency medical service team arrived, they detected a severe hypoglycemia at $1.7 \mathrm{mmol} / \mathrm{l}(0.31 \mathrm{~g} / \mathrm{l})$. After intravenous administration of $20 \mathrm{~g}$ of glucose (40 $\mathrm{ml}$ of Glucose $50 \%$ ) the patient normalized his capillary blood glucose value $(5.2 \mathrm{mmol} / \mathrm{l}$ or $0.94 \mathrm{~g} / \mathrm{l}$ ) and became less agitated. He fully regained consciousness after a couple of minutes but he was experiencing a complete circumstantial amnesia. The patient was taken to Lausanne University Hospital for surveillance and a complete blood test. He was not known as diabetic and was not taking any drug known to cause hypoglycemia. He and his family confirmed that he had not been using exogenous insulin or other antidiabetic drugs. His medical history was significant for biological aortic valve replacement, cardiovascular disease with acute ischemic stroke and a partial gastrectomy for a gastro-intestinal stromal tumor (GIST) in 2009, followed by a 3 years therapy of daily Imatinib. The treatment was stopped in 2012 and since then there were no sign of radiological relapse. At the time of presentation, the patient was taking the next drugs: Pantoprazole, Aspirin, Clopidogrel, Lisinopril, Rosuvastatin, Calcium/D3 supplements and weekly intramuscular Vitamin B12 injections. Result of routine investigations, including renal, liver and thyroid function tests, were not significant (Table 1). A chronic

\begin{tabular}{|c|c|c|c|c|c|}
\hline \multirow[b]{2}{*}{ Laboratory data } & \multirow{2}{*}{$\begin{array}{l}\text { Patient's } \\
\text { value }\end{array}$} & \multirow{2}{*}{$\begin{array}{l}\text { Reference } \\
\text { range }\end{array}$} & \multicolumn{3}{|c|}{72 hours fast test } \\
\hline & & & $\begin{array}{c}\text { At } 2 \\
\text { hours }\end{array}$ & $\begin{array}{l}\text { At } 16 \\
\text { hours }\end{array}$ & $\begin{array}{l}\text { At } 70 \\
\text { hours }\end{array}$ \\
\hline Glucose (mmol/l) & 5 & $3.7-5.6$ & $3.3^{*}$ & $2.4^{*}$ & $2.4^{*}$ \\
\hline Insulin level (mIU/l) & 269 & $3-13$ & 867 & $>1000$ & 520 \\
\hline C-peptide $\mu \mathrm{g} / \mathrm{l}$ & 10.5 & $1-3$ & 4.9 & 6.8 & 3.9 \\
\hline $\begin{array}{c}\text { Insulin auto- } \\
\text { antibodies (kIU/I) }\end{array}$ & $>50$ & $<0.4$ & - & - & - \\
\hline IGF II (ng/ml) & 561 & $373-1000$ & - & - & - \\
\hline $\begin{array}{c}\text { Beta-OH-butyrate } \\
\mu \mathrm{g} / \mathrm{l}\end{array}$ & 1468 & $58-170$ & - & - & - \\
\hline $\mathrm{HbA1c}(\%)$ & 5.5 & $4.9-6.5$ & - & - & - \\
\hline TSH (mIU/l) & 1.59 & $0.27-4.2$ & - & - & - \\
\hline ACTH (ng/l) & 9 & $4-30$ & - & - & - \\
\hline Cortisol (nmol/l) & 357 & $210-560$ & - & - & - \\
\hline Hemoglobin (g/l) & 98 & $133-177$ & - & - & - \\
\hline AST (IU/I) & 67 & $14-50$ & - & - & - \\
\hline ALT (IU/I) & 80 & $11-60$ & - & - & - \\
\hline Creatinine $(\mu \mathrm{mol} / \mathrm{l})$ & 80 & $62-106$ & - & - & - \\
\hline \multicolumn{6}{|c|}{$\begin{array}{l}\text { * The patient had no neuroglycopenic symptoms } \\
\text { Abbreviations: ACTH: Adrenocorticotropic Hormone; ALT: Alanine } \\
\text { Aminotransferase; AST: Aspartate Aminotransferase; Beta-OH-Butyrate: Beta- } \\
\text { Hydroxy-Butyrate; C-Peptide: Connecting Peptide; Hba1c: Hemoglobin A1c; IGF } \\
\text { II: Insulin-Like Growth Factor II; TSH: Thyroid Stimulating Hormone. }\end{array}$} \\
\hline
\end{tabular}

Table 1: Laboratory test results with the most relevant results of the 72 hours fast test.

anemia was present, probably secondary to a vitamin B12 deficiency in the context of partial gastrectomy. We performed adrenocorticotropic hormone (ACTH) and cortisol dosages followed by a Synacthen test: the results were normal. Dosage of insulin-like growth factor II (IGF-II) was negative which excluded a tumor-induced hypoglycemia; there was no trace of sulfonylurea drugs in the patient's blood. Other immunological findings of the patient showed elevated serum immunoglobulin $\mathrm{G}(\mathrm{IgG})$ level at $17.76 \mathrm{~g} / \mathrm{l}$ (normal $5.7-12.5 \mathrm{~g} / \mathrm{l}) ; \mathrm{IgM}$ was also elevated at $8.51 \mathrm{~g} / \mathrm{l}$ (normal 0.34-2.41 g/l) and $\mathrm{IgA}$ was $3.41 \mathrm{~g} / \mathrm{l}$ (normal 0.71-4.07 g/l) but no evidence of monoclonal gammopathy. We evaluated all recent and ancient computed tomography (CT) scans available since the diagnosis of GIST in order to find an element in favor of an insulinoma but no pancreatic or retroperitoneal mass was detected. Recent brain magnetic

${ }^{*}$ Corresponding author: Adrian Stefanescu, Department of Internal Medicine, University Hospital Lausanne, Switzerland, Tel: +41 2131411 11; E-mail: adrian.stefanescu@chuv.ch

Received December 18, 2017; Accepted January 22, 2018; Published January 27, 2018

Citation: Stefanescu A, Bart P (2018) A Case of Autoimmune Hypoglycemia in Switzerland. J Clin Case Rep 8: 1068. doi: 10.4172/2165-7920.10001068

Copyright: (c) 2018 Stefanescu A, et al. This is an open-access article distributed under the terms of the Creative Commons Attribution License, which permits unrestricted use, distribution, and reproduction in any medium, provided the original author and source are credited. 
resonance imaging (MRI) showed no pituitary mass or other intracranial abnormality except the ancient ischemic stroke lesions. During the first 48 hours following hospitalization, the patient continued to have mild asymptomatic hypoglycemic episodes $(3-5 \mathrm{mmol} / \mathrm{l}$ or $0.5-0.9$ $\mathrm{g} / \mathrm{l})$. In this case we initially had a clinical suspicion of endogenous hyperinsulinism, so we performed a 72 hours fast test. In order to have a positive test, we need to objectify the Whipple's triad and an insulin/ C-peptide ratio below 1 . The Whipple's triad is positive if biochemical hypoglycemia is accompanied by neuroglycopenic symptoms, with disappearance of these symptoms after correction of the hypoglycemia. In order to exclude factitious hypoglycemia, the insulin/C-peptide ratio should be determined at the time point when Whipple's triad is positive; in the case of insulinoma the ratio has been reported to be $<1$. During the 72 hours fast test, the patient developed frequent but asymptomatic hypoglycemia with plasma blood glucose level varying from 2.4 and $4.9 \mathrm{mmol} / \mathrm{l}(0.4$ and $0.8 \mathrm{~g} / \mathrm{l})$. The corresponding serum insulin levels were very high, varying from 269 to $867 \mathrm{mIU} / \mathrm{l}$ (reference range of 3-13 mIU/l); the insulin connecting peptide (C-peptide) levels were also high $(10.5 \mu \mathrm{g} / \mathrm{l}$ for a reference range of $1-3 \mu \mathrm{g} / \mathrm{l})$, and plasma beta-hydroxybutyrate was high $(1468 \mu \mathrm{g} / \mathrm{l}$ for a reference range of 58 $170 \mu \mathrm{g} / \mathrm{l})$. Because the patient had very high immunoreactive insulin, free insulin was assayed using polyethylene glycol (PEG) precipitation according to the method of Nakagawa et al to rule out endogenous hyperinsulinism [6]. Recovery after precipitation with PEG was $<2.6 \%$, result in favor of the presence of IAA. We measured the level of these antibodies: they were elevated $>50 \mathrm{kIU} / \mathrm{l}$ for a reference range $<0.4$ $\mathrm{kIU} / \mathrm{l}$. These findings were highly suggestive of insulin autoimmune syndrome (IAS) being the cause of the hypoglycemia. The patient was advised to take frequently meals in small quantities in order to maintain a more consistent blood glucose level and to perform daily monitoring of capillary blood glucose. After the hospital discharge, a glucagon injection kit and additional treatment with steroids were prescribed. Initially at $60 \mathrm{mg}$ daily dose, the oral prednisolone dose was tapered to $5 \mathrm{mg} /$ day after 3 months. During the follow-up, the episodes of hypoglycemia gradually disappeared, a moderate decrease in serum insulin levels was also observed but the level was still high $(88 \mathrm{mIU} / \mathrm{l})$. Unfortunately, the patient died after 4 months of follow-up due to an infectious pneumonia.

\section{Discussion}

In this report, we describe a white man with symptomatic hypoglycemia whose medical work-up revealed an excessively elevated serum insulin level $(867 \mathrm{mIU} / \mathrm{l})$. The need to measure IAA in patients with extraordinarily high measured levels of total insulin is essential because of the possible artifactual elevation (in a conventional insulin immunoassay) caused by IAA. In the present case, the elevated IAA level ( $>50 \mathrm{kIU} / \mathrm{l})$ confirmed the diagnosis of autoimmune hypoglycemia and allowed to avoid unnecessary surgical intervention. Since the patient's health status could not permit more invasive procedures (e.g. endoscopic ultrasound with pancreatic biopsy, surgery), we did not formally exclude insulinoma, but the recent abdominal CT-scans and the negative 72 hours fast test were not in favor of this diagnosis. Conservative therapy, coupled with immunosuppression, permitted to stabilize patient's blood glucose level and to avoid other episodes of severe hypoglycemia. The supposed mechanism for hypoglycemia in IAS is a mismatch between blood glucose and free insulin concentration secondary to the binding and the release of secreted insulin related to autoimmune antibodies. Following a meal or oral glucose intake, high blood glucose level induces insulin secretion. Autoimmune antibodies bind to these insulin molecules, rendering them unavailable to exert their effects. This binding reduces the initial insulin response, resulting in hyperglycemia and further insulin secretion. As the glucose concentration begins to fall, insulin secretion also decreases but the antibody-bound insulin molecules spontaneously dissociate at this time, resulting in a free insulin level inappropriate for the glucose concentration, evoking hypoglycaemia [6,7].

About half of IAS patients report recent exposure to medications, with over $90 \%$ of offending agents containing a thiol group such as Methimazole (anti-thyroid agent), Penicillamine, Glutathione, Hydralazine, Procainamide and Isoniazid $[4,8]$. The subject described in the present report was taking two drugs that contained active thiol metabolites, namely Pantoprazole and Clopidogrel. There are case reports of IAS in patients using thiol-containing proton pump inhibitors including Pantoprazole and Omeprazole $[9,10]$. The mechanism of development of IAS with thiol group-containing drug is not entirely clear. Different approaches for management of IAS have been described. The first line of treatment is implementing lifestyle modification as small frequent meals with low-glycemic index carbohydrates. Any potentially incriminating medication should be discontinued. Glucocorticoid oral therapy ( $1 \mathrm{mg} / \mathrm{kg} /$ day) can improve glycemic control and diminish the levels of IAA. Other medications such as Acarbose can decrease carbohydrate digestion and absorption. Somatostatin, diazoxide and even partial pancreatectomy have been employed in a attempt to limit insulin secretion [5,7] None of these therapy has been universally successful. For refractory cases, plasmapheresis or Rituximab have been used with good results $[11,12]$. Previous studies already showed that in type 1 diabetic patients who developed insulin antibodies to exogenous insulin, Rituximab has been successfully used to suppress the production of insulin antibodies. A single course of Rituximab was enough to obtain a significant level of insulin antibodies suppression that has been noted to last, in a subgroup of patients, up to 3 years despite continuing insulin therapy [13].

\section{Conclusion}

Here we report the case of a white man with potentially life threatening hypoglycemia due to IAS. Even though primary investigation of hypoglycemia in non-diabetic patients is always focused on insulinoma, IAA measurement should be always performed because IAS is a cause of hypoglycemia that can be cured without surgery in the majority of cases.

\section{References}

1. Hirata $Y$, Ishizu H, Ouchi N, Motomura M, Abe M, et al. (1970) Insulin autoimmunity in a case of spontaneous hypoglycemia. J Jpn Diabetes Soc 13: 312-320.

2. Takayama-Hasumi S, Eguchi Y, Sato A, Morita C, Hirata Y (1990) Insulin autoimmune syndrome is the third leading cause of spontaneous hypoglycemic attacks in Japan. Diabetes Res Clin Pract 10: 211-214.

3. Uchigata $Y$ (1992) Strong association of insulin autoimmune syndrome with HLA-DR4. Lancet 339: 393-394.

4. Uchigata $Y$, Hirata $Y$ (1999) Insulin autoimmune syndrome (IAS, Hirata disease). Ann Med Interne 150: 245-253.

5. Lupsa BC, Chong AZ, Cochran AK, Soos MA, Semple RK, et al. (2009) Autoimmune forms of hypoglycemia. Medicine (Baltimore) 88: 141-153.

6. Nakagawa S, Nakayama H, Sasaki T, Yoshino K, Yu YY, et al. (1973) A simple method for the determination of serum free insulin levels in insulin-treated patients. Diabetes 22: 590-600.

7. Redmon JB, Nuttall FQ (1999) Autoimmune hypoglycemia. Endocrinol Metab Clin North Am 28: 603-618.

8. Yamada T, Imai J, Ishigaki Y, Hinokio Y, Oka Y, et al. (2007) Possible relevance of HLA-DRB1*0403 haplotype in insulin autoimmune syndrome induced by alpha-lipoic acid, used as a dietary supplement. Diabetes Care 30: e131. 
9. Gopal K, Priya G, Gupta N, Praveen EP, Khadgawat R (2013) A case of autoimmune hypoglycemia outside Japan: Rare, but in the era of expanding drug-list, important to suspect. Indian J Endocrinol Metab 17: 1117-1119.

10. Sahni P, Trivedi N, Omer A (2016) Insulin autoimmune syndrome: a rare cause of postprandial hypoglycemia. Endocrinol Diabetes Metab Case Rep 2016.

11. Saxon DR, McDermott MT, Michels AW (2016) Novel management of insulin autoimmune syndrome with rituximab and continuous glucose monitoring. J Clin Endocrinol Metab 101: 1931-1934.

12. Church D, Hunter RW, Lyall M, Clarke C, Vliegenthart ADB, et al. (2017) Resolution of hypoglycemia and cardiovascular dysfunction after rituximab treatment of insulin autoimmune syndrome. Diabetes Care 40: e80-e82.

13. Yu L, Herold K, Steinrauf HK, McGee PL, Bundy B, et al. (2011) Rituximab selectively suppresses specific islet antibodies. Diabetes 60: 2560-2565. 